${ }^{1}$ Department of Prosthodontics, School of Dentistry, University of Taubaté, Taubaté, Brazil.

${ }^{2}$ Department of Materials and Technology, School of Engineering of Guaratinguetá, São Paulo State University, Guaratinguetá, Brazil.

Corresponding author:

Rafael Pino Vitti

(iD) https://orcid.org/0000-0001-6366-5868 University of Taubaté

09 Rua dos Operários, Taubaté, SP CEP: $12020-270$

Phone/Fax: 55-12-3629-2130 e-mail: rafapvitti@gmail.com

Received: January 20, 2019

Accepted: June 28, 2019

\section{Stress distribution in the peri-implant area of pure titanium and titanium-zirconium small implants}

Tatiana de Andrade Sabino ${ }^{1}$, Laís Regiane da Silva-Concílio ${ }^{1}$, Ana Christina Elias Claro Neves ${ }^{1}$, Ana Paula Rosifini Alves Claro ${ }^{2}$, Marina Amaral ${ }^{1}$, Rafael Pino Vitti ${ }^{1, *}$, Cristiane Aparecida de Assis Claro ${ }^{1}$

Aim: In dental implant treatment, there is a demand for mechanically stronger implants. Despite the existence of several studies showing the clinical success of narrow diameter implants, most of them are based on pure titanium (cpTi) alloys. There is a few clinical evidences of the success rate of titanium-zirconium (TiZr) narrow diameter implants. The aim of this study was to evaluate the stress distribution in the peri-implant area of narrow diameter cpTi and TiZr implants under axial and oblique loads. Methods: Photoelastic models were produced using epoxy resin (PL2, Vishay Precision Group) from a master model. The implants (cpTi and TiZr; Straumann AG) had $3.3 \mathrm{~mm}$ in diameter and $12 \mathrm{~mm}$ in height. Loads of $100 \mathrm{~N}$ and $200 \mathrm{~N}$ were applied to the abutment at angles of $0^{\circ}$ (axial), $10^{\circ}, 20^{\circ}$, and $30^{\circ}$ (oblique). A circular polariscope (Eikonal) was used under dark field white-light configuration. The isochromatic fringes were analyzed in the peri-implant region in 5 areas, using ASTM table with isochromatic fringes; cervical-mesial, cervical-distal, mid-mesial, mid-distal and apical. Results: In general, under axial and oblique loads, the stress in the TiZr implant was lower than in the cpTi implant. The load of $200 \mathrm{~N}$ produced the highest stress values in cpTi and TiZr implants. In both implants and loads, the fringes were located more in apical area at all angles evaluated. Conclusion: It can be concluded that for small implants, the load inclination and intensity change the pattern of stress distribution and the cpTi implant exhibited the highest peri-implant stress.

Keywords: Dental implants. Dental stress analysis. Stress, mechanical. 


\section{Introduction}

Narrow diameter implants are indicated as a clinical alternative for patients with a limited alveolar ridge or limited space. The osseointegration of commercially pure titanium (cpTi) with surrounding bone emphasize its clinical success, however, its mechanical strength can be insufficient when narrow diameter implants $(<3.5 \mathrm{~mm})$ are used, since the diameter directly influences the fatigue strength ${ }^{1}$. One approach to overcome this problem is strengthening the mechanical properties of the titanium by alloying it with other materials, such as zirconium ( $\mathrm{Zr}$ ). This strategy increased the elastic modulus, hardness as well as tensile and fatigue strength, maintaining the biocompatibility similar to cpTi both in laboratory ${ }^{2,3}$ and clinical studies ${ }^{4,5}$.

The cpTi implants with a narrow diameter have a lower mechanical strength compared with titanium-zirconium (TiZr) implants. These characteristics can influence the magnitudes of stress and consequently the outcomes of peri-implant therapy 4 . The addition of more than $50 \% \mathrm{Zr}$ to $\mathrm{TiZr}$ alloy increases its resistance by two and a half fold ${ }^{5}$. Zirconium also reduces the melting point of the alloy and associated costs $^{6}$. Another advantage of the addition of zirconium in titanium alloys is an improvement in the corrosion resistance with the formation of a stable oxide layer on the surface of the alloy ${ }^{7,8}$. In a study investigating the effect of the percentage by weight of Zr on the mechanical properties of TiZr alloy samples, it was found that the TiZr samples had higher micro-hardness values than Ti samples at all concentrations of $\mathrm{Zr}^{9}$.

The success rate of TiZr narrow diameter implants has been shown to be similar to that of regular diameter cpTi implants ${ }^{10}$. The TiZr alloy has been classified as non-cytotoxic material ${ }^{11}$. Furthermore, TiZr alloy has a monophasic a-structure like titanium and it allows performing surface modification using the conventional sandblasting and acid etching procedures ${ }^{12}$. Despite the reported benefits of narrow diameter TiZr implants for use in narrow areas, particularly the upper resistance of $\mathrm{TiZr}$ compared with that of $\mathrm{cpTi}^{2-5}$, literature is scarce regarding the evaluation stress distribution patterns of TiZr alloy implants in surrounding bone. Thus, it was of great interest to understand if the microtextured TIZr implant surface would present similar peri-implant stress compared with the cpTi.

The aim of this study was to assess the peri-implant stress of narrow diameter $(3.3 \mathrm{~mm}) \mathrm{cpTi}$ and TiZr implants under load $(100 \mathrm{~N}$ and $200 \mathrm{~N})$ in axial $\left(0^{\circ}\right)$ and oblique direction centralized $\left(\right.$ at $10^{\circ}, 20^{\circ}$, and $30^{\circ}$ ) to the long axis of the implants. The hypothesis was that there will be difference in the number of high-intensity fringes between the type of dental implants and the loads applied.

\section{Materials and Methods}

Two photoelastic models were produced using epoxy resin (PL2, Vishay Precision Group, Wendell, NC, USA) from a master model; one with a cpTi implant and the other with a TiZr implant. The cpTi implant (Institut Straumann AG, Peter Merian, Basel, Switzerland) comprised the following: nitrogen 0:05\%; carbon 0:08\%; hydrogen 
$0.015 \%$; iron $0.50 \%$; oxygen 0:40\%; maximum waste $0.1 \%$ each; total maximum waste $0.4 \%$, and $\mathrm{Ti}$ (comprising the remaining balance). The chemical composition of the TiZr implant (Institut Straumann AG, Peter Merian, Basel, Switzerland) was 85\% Ti and $15 \% \mathrm{Zr}$. Both implants were of the bone level type, $3.3 \mathrm{~mm}$ in diameter and $12 \mathrm{~mm}$ in height, SLActive, and had a narrow connection. Healing abutments were positioned on both implants.

The circular polariscope (Eikonal, São Paulo, Brazil) was used in the dark field configuration; therefore, the polarizer and analyzer were crossed. The optical axes of the quarter wave plates were also crossed and made an angle of $45^{\circ}$ with those of the polarizer and the analyzer. The photoelastic models were observed before each test. The circular polariscope was utilized to verify the absence of residual stress and also for recording stresses (isochromatic fringes) during rehearsals. The polariscope was adapted to a universal test machine (AG-X 50 kN, Shimadzu, Tokyo, Japan) with a $5 \mathrm{kN}$ load cell for implementing centralized and oblique axial compressive load at a crosshead speed of $0.5 \mathrm{~mm} / \mathrm{min}$. Eight trials were performed with simulated forces $(100 \mathrm{~N}$ and $200 \mathrm{~N})$ and at a central axial oblique of $0^{\circ}, 10^{\circ}, 20^{\circ}$, and $30^{\circ}$ to the long axis of the implants.

Stress was identified with the aid of a American Society for Testing and Materials (ASTM) table which lists the sequence of colors and values for the orders of isochromatic fringes in the photoelastic material observed in a circular polariscope; in a dark field configuration with white light, under progressive increasing load (black=0; gray $=0.28$; light yellow $=0.6$; orange $=0.79$; intense red $=0.9$; red-blue transition=1.0; intense blue=1.06; blue-green=1.2; green-yellow=1.38; orange $=1.62$; pink-red=1.81; red-green transition=2.0; green=2.33; green-yellow $=2.5$; red=2.67; red-green transition=3.0; green=3.1; pink=3.6; pink-green transition=4.0; green=4.13) ${ }^{13}$. The following peri-implant areas were evaluated: cervical-mesial (CM), cervical-distal (CD), mid-mesial (MM), mid-distal (MD) and apical (A).

\section{Results}

The results (magnitude of stress) around the cpTi and TiZr implants (incline $=0^{\circ}, 10^{\circ}$, $20^{\circ}$, and $30^{\circ}$ ), which illustrate the stresses resulting from the $100 \mathrm{~N}$ and $200 \mathrm{~N}$ loads, were based on the number of high-intensity fringes in the stress patterns in the photoelastic models (Figures 1 and 2).

Table 1 shows that for the majority of the areas evaluated, the values of the isochromatic fringe order around the TiZr implant were equal to or lower than those observed in case of the cpTi implant. The differences in stress between the two implants were small, with the exception of a few regions such as the CM and CD under an axial force of $200 \mathrm{~N}$. In these areas, the TiZr implant demonstrated considerably lower stresses ( 0.45 and 0.45 , respectively) compared with the cpTi implant (1.2 in both areas). 

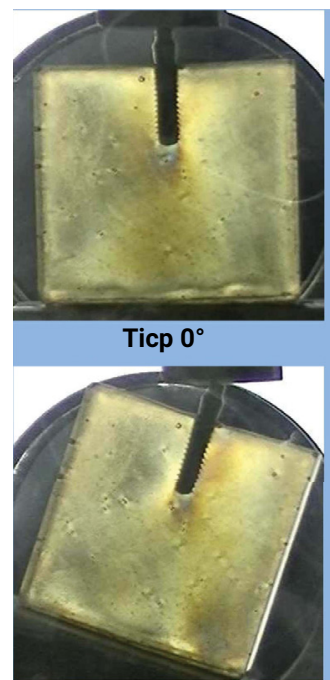

Ticp $20^{\circ}$

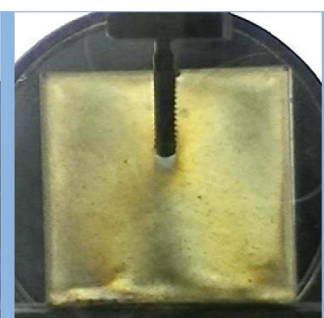

$$
\operatorname{TiZr} 0^{\circ}
$$

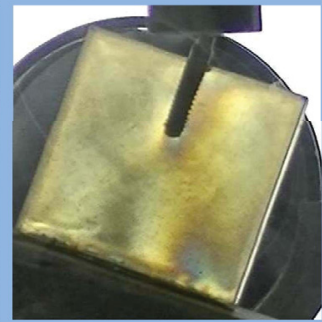

$\operatorname{TiZr} 20^{\circ}$

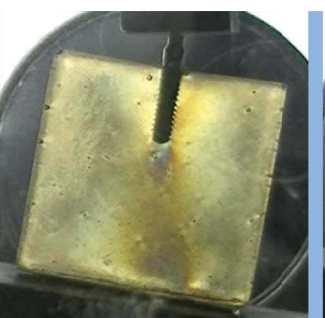

Ticp $10^{\circ}$

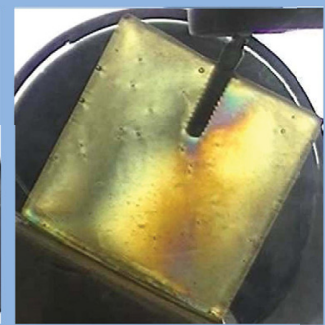

Ticp $30^{\circ}$

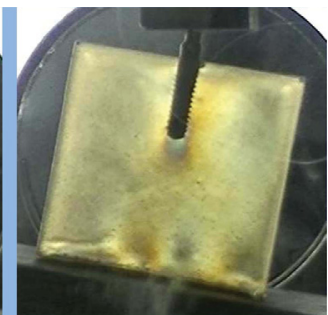

$\operatorname{TiZr} 10^{\circ}$

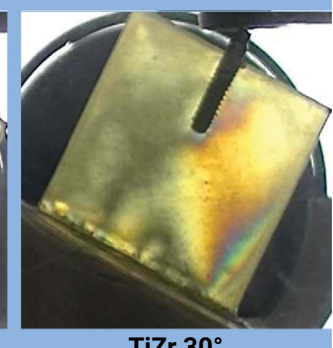

$\operatorname{TiZr} 30^{\circ}$

Figure 1. Photoelastic models with load of $100 \mathrm{~N}$.
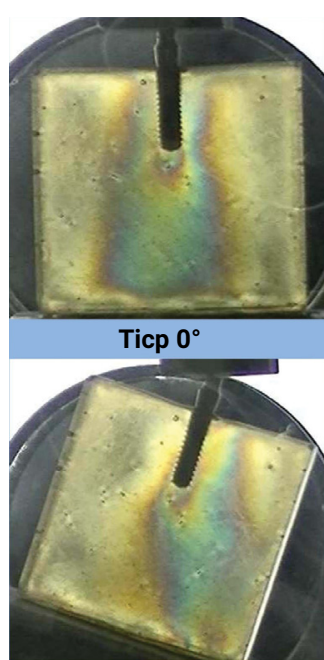

Ticp $20^{\circ}$

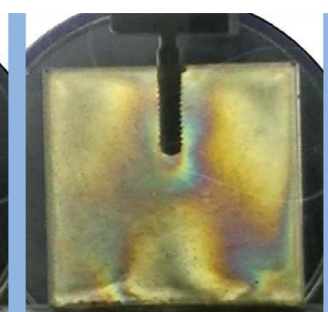

$\operatorname{TiZr} 0^{\circ}$

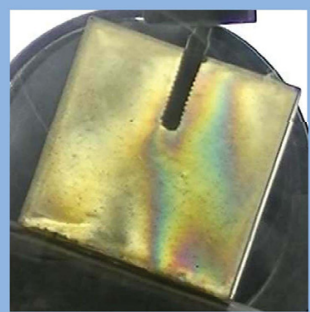

$\operatorname{TiZr} 20^{\circ}$
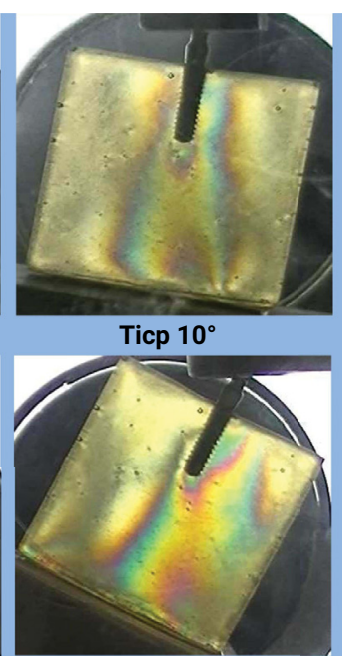

Ticp $30^{\circ}$

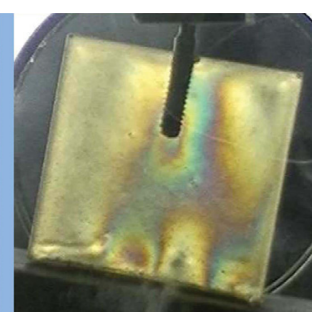

TiZr $10^{\circ}$

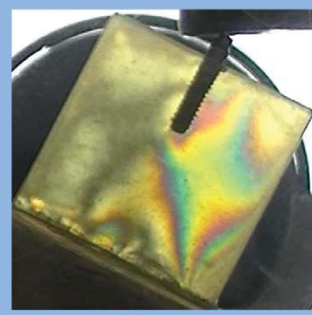

$\operatorname{TiZr} 30^{\circ}$

Figure 2. Photoelastic models with load of $200 \mathrm{~N}$.

\section{Discussion}

The proposed hypothesis was accepted since both implants increased stress. TiZr implant showed the highest values of stresses (fringe orders). Moreover, the apical peri-implant area received the greatest stress, except when the inclination of the implant increased to $30^{\circ}$. In this case the highest stresses were observed in the contralateral region of the application of force $(\mathrm{CM})$. 
Table 1. cpTi and TiZr peri-implant stresses (fringe orders) with loads of $100 \mathrm{~N}$ and $200 \mathrm{~N}$.

\begin{tabular}{|c|c|c|c|c|c|c|c|c|}
\hline \multicolumn{9}{|c|}{$100 \mathrm{~N}$} \\
\hline Area & $\begin{array}{c}\text { cpTi } \\
0^{\circ}\end{array}$ & $\begin{array}{c}\mathrm{TiZr} \\
0^{\circ}\end{array}$ & $\begin{array}{c}\text { cpTi } \\
10^{\circ}\end{array}$ & $\begin{array}{l}\mathrm{TiZr} \\
10^{\circ}\end{array}$ & $\begin{array}{c}\text { cpTi } \\
20^{\circ}\end{array}$ & $\begin{array}{l}\mathrm{TiZr} \\
20^{\circ}\end{array}$ & $\begin{array}{c}\mathrm{cpTi} \\
30^{\circ}\end{array}$ & $\begin{array}{l}\text { TiZr } \\
30^{\circ}\end{array}$ \\
\hline $\mathrm{CM}$ & 0.28 & 0.28 & 0.60 & 0.45 & 0.79 & 0.45 & 1.38 & 1.20 \\
\hline MM & 0.79 & 0.60 & 0.79 & 0.60 & 0.90 & 0.90 & 1.00 & 0.90 \\
\hline A & 1.20 & 1.20 & 1.38 & 1.20 & 1.20 & 1.20 & 1.20 & 1.06 \\
\hline MD & 0.79 & 0.60 & 0.60 & 0.45 & 0.45 & 0.45 & 0.28 & 0.28 \\
\hline$C D$ & 0.45 & 0.28 & 0.45 & 0.28 & 0.28 & 0.28 & 0.28 & 0.28 \\
\hline \multicolumn{9}{|c|}{$200 \mathrm{~N}$} \\
\hline Area & $\begin{array}{c}\text { cpTi } \\
0^{\circ}\end{array}$ & $\begin{array}{c}\mathrm{TiZr} \\
0^{\circ}\end{array}$ & $\begin{array}{c}\mathrm{cpTi} \\
10^{\circ}\end{array}$ & $\begin{array}{l}\mathrm{TiZr} \\
10^{\circ}\end{array}$ & $\begin{array}{c}\mathrm{cpTi} \\
20^{\circ}\end{array}$ & $\begin{array}{l}\mathrm{TiZr} \\
20^{\circ}\end{array}$ & $\begin{array}{c}\mathrm{cpTi} \\
30^{\circ}\end{array}$ & $\begin{array}{l}\mathrm{TiZr} \\
30^{\circ}\end{array}$ \\
\hline $\mathrm{CM}$ & 1.20 & 0.45 & 1.38 & 1.38 & 1.81 & 1.81 & 2.50 & 2.33 \\
\hline MM & 1.38 & 1.20 & 1.38 & 1.38 & 1.81 & 1.81 & 2.33 & 1.81 \\
\hline A & 2.33 & 2.00 & 2.33 & 2.00 & 2.00 & 2.00 & 2.33 & 1.81 \\
\hline MD & 1.38 & 1.20 & 1.06 & 0.60 & 0.60 & 0.60 & 0.45 & 0.45 \\
\hline$C D$ & 1.20 & 0.45 & 0.79 & 0.28 & 0.28 & 0.28 & 0.45 & 0.28 \\
\hline
\end{tabular}

The TiZr peri-implant stresses (fringe orders) that are lower than cpTi peri-implant stresses are highlighted in bold.

Several factors have been associated with changes in peri-implant stress ${ }^{14}$. These include bone density ${ }^{15}$, the bone ridge $^{16}$, type of material and intermediate prosthetic, occlusal relationship, implant connections ${ }^{16,17}$ and the length and diameter of the implant ${ }^{18}$. The implants investigated in this study have characteristics that in favor of the reduction of stress. Implants are intraosseous because they have lower stresses than those placed at the gingival level ${ }^{19}$, and their internal hexagon produces lower stresses due to its geometry and connection stability ${ }^{20}$.

The TiZr implant demonstrated superior tensile strength (953 $\mathrm{MPa})^{21}$ and fatigue strength $(230 \mathrm{~N})^{22}$ compared with the cpTi implant (680 MPa ${ }^{21}$ and $205 \mathrm{~N}^{22}$, respectively). This is because the modulus of elasticity of the TiZr implant (100 GPa) is smaller than that of the cpTi implant $(110 \mathrm{GPa})^{19}$. The difference in the modulus of elasticity between the TiZr and cpTi implants has been attributed to minor stresses in TiZr peri-implants observed using finite elements ${ }^{19}$ and strain gage ${ }^{23}$. This also supports the results of the present study, which identified lower stresses in the TiZr implant through photoelasticity. The alloys used in implants have to combine high mechanical strength with low modulus, and should be located close to the bone at 30 to $40 \mathrm{GPa}^{24}$ in order to avoid stress shielding and subsequent bone resorption. Therefore, the fact that the TiZr implant has a lower modulus of elasticity than the cpTi implant might also explain the highest quality of bone observed around this implant when compared with the $\mathrm{cpTi}$ implant ${ }^{25}$ and the minimal bone resorption within the first two years after implantation ${ }^{26}$. Although the TiZr implant has a lower elastic modulus than the cpTi implant, it is still very different from that of bone. Therefore, the future development of superior alloys requires those with similar characteristics to the alloys in this present study, but with a closer proximity to the bone's modulus of elasticity. 
Qualitative analysis of the stresses indicated differences in stress between peri-implants of the same geometry in the majority of the analyzed areas. In $80 \%$ of the cases, at $0^{\circ}$ and $10^{\circ}$, the stress was lower in the TiZr implant than in the cpTi implant, independent of the applied force. These cases exemplify situations similar to the angulation of the teeth in individuals with an average of $9^{\circ}$ (mesiodistal) to the upper lateral incisors and $3^{\circ}$ slope (buccolingual), according to Andrews' classification. The four lower incisors have an angulation (mesiodistal) average of $2^{\circ}$ and a tilt (buccolingual) average of $-1^{\circ 27}$. The lower stress observed with the use of the TiZr implant in this study is favorable because the lower stress in the peri-implant bone reduces the potential for bone resorption and increases the commitment of the shortor long-term implant. The implant inclination in these regions should not exceed the specified value, however, in many cases implants are inserted at greater slopes to compensate for differences in bone sagittal maxillomandibular relationships.

In the present study, the highest stress levels were recorded in the apical region, except at an angle of $30^{\circ}$. In this case the stress was higher in the $\mathrm{CM}$ region. When both implants were oriented at $10^{\circ}, 20^{\circ}$, and $30^{\circ}$, stresses tended to increase gradually with increasing load, and were concentrated in the contralateral side (CM and MM) of the applied load. However, on the opposite side (CD and MD), the application of load resulted in a gradual decrease in the stress under the same conditions.

The findings of previous photoelastic analysis studies of peri-implant stresses applying oblique forces are consistent with the present findings and demonstrate that the higher stresses generated are due to oblique loading ${ }^{27}$. In the previous studies, the slopes varied accordingly: $0^{\circ}$ and $10^{\circ}, 0^{\circ}$ and $20^{\circ} 28,0^{\circ}$ and $30^{\circ 2}$, and $0^{\circ}$ and $45^{\circ 27}$.

The masticatory load of each edentulous region under consideration for rehabilitation should be considered when selecting the implant diameter. The bite force in the region of the incisors is 14 to $25 \mathrm{kgf}$ and varies according to gender and age ${ }^{1}$. The present study utilized forces of $100 \mathrm{~N}$ and $200 \mathrm{~N}$ applied to the loads and these forces were consistent with those used in previous photoelastic analysis studies $^{1,27-29}$. There is a few peri-implant stress analysis studies in literature that investigated narrow diameter cpTi and TiZr implants. While this present study results supports recently published outcomes from in vitro studies, clinical studies are still required to confirm these findings.

In conclusion, compared with the cpTi implant, the $\mathrm{TiZr}(15 \% \mathrm{Zr})$ implant is associated with lower stress in the majority of peri-implant regions when subjected to a variety of loads and angles.

\section{References}

1. Allum SR, Tomlinson RA, Joshi R. The impact of loads on standard diameter, small diameter and mini implants: a comparative laboratory study. Clin Oral Implants Res. 2008 Jun;19(6):553-9. doi: 10.1111/j.1600-0501.2007.01395.x

2. Taddei EB, Henriques VAR, Silva CRM, Cairo CAA. Production of new titanium alloy for orthopedic implants. Mater Sci Eng C. 2004 Nov;24(5):683-7. 
3. Li SJ, Yang R, Niinomi M, Hao YL, Cui YY. Formation and growth of calcium phosphate on the surface of oxidized Ti-29Nb-13Ta-4.6Zr alloy. Biomaterials. 2004 Jul; 25(13):2525-32.

4. Grandin HM, Berner S, Dard M. A review of titanium zirconium (TiZr) alloys for use in endosseous dental implants. Materials. 2012 Aug;5(8):1348-60.

5. Kobayashi E, Matsumoto S, Doi H, Yoneyama T, Hamanaka H. Mechanical properties of the binary titanium-zirconium alloys and their potential for biomedical materials. J Biomed Mater Res. 1995 Aug;29(8):943-50.

6. Ho WF, Chen WK, Wu SC, Hsu HC. Structure, mechanical properties and grindability of dental Ti-Zr alloys. J Mater Sci Mater Med. 2008 Oct;19(10):3179-86. doi: 10.1007/s10856-008-3454-X.

7. Niinomi M. Recent research and development in titanium alloys for biomedical applications and healthcare goods. Sci Technol Adv Mater. 2003 Sep;4(5):445-54.

8. Geetha M, Singh AK, Asokamani R, Gogia AK. Ti based biomaterials, the ultimate choice for orthopedic implants - A review. Prog Mater Sci. 2009 May;54(3):397-425.

9. Correa DR, Vicente FB, Donato TA, Arana-Chavez VE, Buzalaf MA, Grandini CR. The effect of the solute on the structure, selected mechanical properties, and biocompatibility of Ti-Zr system alloys for dental applications. Mater Sci Eng C Mater Biol Appl. 2014 Jan;34:354-9.

10. Sohrabi K, Mushantat A, Esfandiari S, Feine J. How successful are small-diameter implants? A literature review. Clin Oral Implants Res. 2012 May;23(5):515-25. doi: 10.1111/j.1600-0501.2011.02410.x.

11. Park YJ, Song YH, An JH, Song HJ, Anusavice KJ. Cytocompatibility of pure metals and experimental binary titanium alloys for implant materials. J Dent. 2013 Dec;41(12):1251-8. doi: 10.1016/j.jdent.2013.09.003.

12. Bernhard N, Berner S, De Wild M, Wieland M. The binary TiZr Alloy - a newly developed Ti alloy for use in dental implants. Forum Implantol. 2009 Jan;5:30-9.

13. Claro CAA, Chagas RV, Neves AC, Silva-Concílio LR. Comparative photoelastic study of dental and skeletal anchorages in the canine retraction. Dental Press J Orthod. 2014 Jan-Feb;19(1):100-5.

14. Meijer HJ, Kuiper JH, Starmans FJ, Bosman F. Stress distribution around dental implants: influence of superstructure, length of implants, and height of mandible. J Prosthet Dent. 1992 Jul;68(1):96-102.

15. Tada S, Stegaroiu R, Kitamura E, Miyakawa O, Kusakari H. Influence of implant design and bone quality on stress/strain distribution in bone around implants: a 3-dimensional finite element analysis. Int J Oral Maxillofac Implants. 2003 May-Jun;18(3):357-68.

16. Torres EM, Barbosa GA, Bernardes SR, de Mattos Mda G, Ribeiro RF. Correlation between vertical misfits and stresses transmitted to implants from metal frameworks. J Biomech. 2011 Jun 3;44(9):1735-9. doi: 10.1016/j.jbiomech.2011.03.032.

17. Goiato MC, Sarauza Arsufi G, de Medeiros RA, Pesqueira AA, da Silva EVF, Sonego MV, et al. Stress distribution of different implant connections associated with multiple implant-supported prostheses. J Med Eng Technol. 2018 Jul;42(5):359-67. doi: 10.1080/03091902.2018.1513575.

18. Baggi L, Cappelloni I, Di Girolamo M, Maceri F, Vairo G. The influence of implant diameter and length on stress distribution of osseointegrated implants related to crestal bone geometry: a three-dimensional finite element analysis. J Prosthet Dent. 2008 Dec;100(6):422-31. doi: 10.1016/S0022-3913(08)60259-0.

19. Eser A, Tonuk E, Akca K, Dard MM, Cehreli MC. Predicting bone remodeling around tissue- and bone-level dental implants used in reduced bone width. J Biomech. 2013 Sep 3;46(13):2250-7. doi: 10.1016/j.jbiomech.2013.06.025.

20. Balfour A, O'Brien GR. Comparative study of antirotational single tooth abutments. J Prosthet Dent. 1995 Jan;73(1):36-43. 
21. Grandin HM, Berner S, Dard M. A review of titanium zirconium (tizr) alloys for use in endosseous dental implants. Materials (Basel). 2012 Aug;5(8):1348-60. doi: 10.3390/ma5081348.

22. Osman RB, Swain MV. A Critical review of dental implant materials with an emphasis on titanium versus zirconia. Materials (Basel). 2015 Mar;8(3):932-58. doi: 10.3390/ma8030932.

23. Wu AY, Hsu JT, Huang HL. An in vitro biomechanical evaluation of a new commercial titanium-zirconium alloy dental implant: a pilot study. Implant Dent. 2014 Oct;23(5):534-8. doi: 10.1097/ID.0000000000000108.

24. Calderon-Moreno JM, Vasilescu C, Drob SI, Ivanescu S, Osiceanu P, Drob P, et al. Microstructural and mechanical properties, surface and electrochemical characterisation of a new $\mathrm{Ti}-\mathrm{Zr}-\mathrm{Nb}$ alloy for implant applications. J Alloys Compd. 2014 Nov;612:398-410. doi: 10.1016/j.jallcom.2014.05.159.

25. Wen B, Zhu F, Li Z, Zhang P, Lin X, Dard M. The osseointegration behavior of titaniumzirconium implants in ovariectomized rabbits. Clin Oral Implants Res. 2014 Jul;25(7):819-25. doi: 10.1111/clr.12141.

26. Barter S, Stone P, Brägger U. A pilot study to evaluate the success and survival rate of titaniumzirconium implants in partially edentulous patients: results after 24 months of follow-up. Clin Oral Implants Res. 2012 Jul;23(7):873-81. doi: 10.1111/j.1600-0501.2011.02231.x.

27. Pellizzer EP, Tonella BP, Ferraço R, Falcón-Antenucci RM, de Carvalho PS, Alves-Rezende MC. Photoelastic stress analysis in screwed and cemented implant-supported dentures with external hexagon implants. J Craniofac Surg. 2010 Jul;21(4):1110-3. doi: 10.1097/SCS.0b013e3181e1b46e.

28. Akça K, Çehreli MC. A photoelastic and strain-gauge analysis of interface force transmission of internal-cone implants. Int J Periodontics Restorative Dent. 2008 Aug;28(4):391-9.

29. Sotto-Maior BS, Senna PM, da Silva-Neto JP, de Arruda Nóbilo MA, Del Bel Cury AA. Influence of crown-to-implant ratio on stress around single short-wide implants: a photoelastic stress analysis. J Prosthodont. 2015 Jan;24(1):52-6. doi: 10.1111/jopr.12171. 